\title{
Temporal $b$-Value Variations throughout a Seismic Faulting Process: The 2008 Taoyuan Earthquake in Taiwan
}

\author{
Cheng-Horng Lin * \\ Institute of Earth Sciences, Academia Sinica, Taipei, Taiwan, ROC \\ Received 8 October 2008, accepted 9 February 2009
}

\begin{abstract}
Temporal $b$-value variations have been completely obtained for the seismic faulting process of the 4 March 2008 Taoyuan earthquake $\left(\mathrm{M}_{\mathrm{L}}=5.2\right)$, southern Taiwan. In addition to triggering several hundred aftershocks, the mainshock was preceded by two groups of foreshocks (64 events) that clustered along the narrow major fault zone. A high $b$-value of $\sim 1.25$, estimated from the foreshock series, representing fault growth, was significantly larger than the $b$-values of 0.80 and 0.81 , obtained respectively from aftershocks and background seismicity. Also there were some pre-shocks (i.e., micro-earthquakes) that occurred one month before the earthquake sequence, with an extremely high $b$-value of $\sim 2.1$. This number might successfully indicate pre-nucleation seismic features in the vicinity of the fault zone. These seismic characteristics are fundamentally very similar to general features such as fracture nucleation and growth observed in rock samples under controlled stress in laboratory experiments, and thus ought to be considered to improve our understanding of crustal fault growth.
\end{abstract}

Key words: Fault growth, $b$-value, Foreshock, Aftershock and 2008 Taoyuan earthquake

Citation: Lin, C. H., 2010: Temporal b-value variations throughout a seismic faulting process: The 2008 Taoyuan earthquake in Taiwan. Terr. Atmos. Ocean. Sci., 21, 229-234, doi: 10.3319/TAO.2009.02.09.01(T)

\section{INTRODUCTION}

Understanding of fault nucleation and growth undoubtedly plays an important role in comprehending earthquake generation mechanisms. To improve our knowledge of faulting processes before large pending earthquakes, temporal variations in $b$-values obtained from earthquake seismicity have been investigated for various tectonic regimes such as: fault zones, volcanic areas, aftershock zones, and subduction zones. However, debate continues on the value of low and high $b$-values obtained before large earthquakes. Numerous studies have revealed that foreshocks often have low $b$-values (Lee et al. 1978; von Seggern 1980; Enescu and Ito 2001). Those observations have been explained on the grounds that decreasing $b$-values before a mainshock might reflect increasing stress in or around the fault zone (Scholz 1968; Main et al. 1992; Amitrano 2003; Schorlemmer et al. 2005; Wu and Chiao 2006). A well-recognized case is the 1975 Haicheng earthquake in China, which showed a low $b$-value of 0.6 in the foreshock series (Wu et al. 1976). However, there are cases when high $b$-values have been observed

\footnotetext{
* Corresponding author

E-mail:lin@earth.sinica.edu.tw
}

before large earthquakes (Comninakis et al. 1968; Gupta et al. 1972). This conflict in $b$-values prior to earthquake nucleation has still not been classified even given detailed examination of $b$-value variations along the Calaveras fault based on large amounts of earthquake data (Parsons 2007).

However, besides field observations of $b$-values, an alternative approach has been to study rock failure processes under laboratory conditions to ensure controlled axial stress for improving our understanding of microscopic fracture nucleation and growth. As a typical example of this approach, Lockner et al. (1991) gives results showing a potential faulting process. They successfully identified micro-cracks in temporal and spatial variations throughout rock failure. In addition, variations in $b$-values were obtained at different stages: namely pre-nucleation, nucleation and fault growth. $b$-value decreases to a minimum at the time of fault nucleation and then recovers to over $50 \%$ of its initial value during fault growth (Lockner et al. 1991). However, such a microcracking process observed under laboratory conditions has not yet been confirmed by field seismic observations.

In this study, the earthquake sequence of an event that occurred on 4 March 2008 in Taoyuan, sourthern Taiwan, 
including the mainshock $\left(\mathrm{M}_{\mathrm{L}}=5.2\right)$ and a cluster of foreshocks as well as aftershocks along a narrow fault zone was recorded by the Central Weather Bureau Seismic Network (CWBSN) of Taiwan. Examinations of temporal $b$-value variations of pre-shocks, foreshocks, and aftershocks on a macroscopic level for the crust show that their seismic characteristics are largely similar to those of microscopic fracture nucleation and growth found in laboratory experiments. These observations might effectively improve our understanding of fault growth phenomenon in the crust.

\section{AFTERSHOCKS AND FORESHOCKS}

On 4 March 2008, an earthquake sequence with a mainshock of $\mathrm{M}_{\mathrm{L}}=5.2$ took place in the Taoyuan area of southern Taiwan (Fig. 1). The Centroid Moment Tensor (CMT) solutions of the mainshock and one of its large aftershocks $\left(\mathrm{M}_{\mathrm{L}}=4.6\right)$ (Table 1) show that the earthquake sequence had a pure thrust-faulting mechanism, which is generally consistent with regional stress features resulting from plate convergence between the Eurasian and Philippine Sea plates in Taiwan (Yeh et al. 1991; Lin 2002). Since this earthquake sequence was recorded by the CWBSN data quality is excellent due to good coverage by its seismic stations (Shin et al. 2000), several hundred aftershocks with local magnitudes $\left(\mathrm{M}_{\mathrm{L}}\right)$ ranging from 0.4 to 4.8 have been precisely located. The seismicity of the well-located aftershocks confirms that the major fault plane strikes NE-SW (Fig. 1a) dipping in a NW-SE direction (Fig. 1b). The size of the major fault plane, estimated from aftershock seismicity, is about $10 \mathrm{~km}$ long along the strike and $10 \mathrm{~km}$ wide in the dip direction.

As well, it is quite interesting to see that the earthquake sequence was preceded by two groups (A and B) of foreshocks that clustered along the major fault plane and dipped in a southeastern direction (Fig. 2). Group A, consisting of 29 micro-earthquakes with local magnitudes $\left(\mathrm{M}_{\mathrm{L}}\right)$ ranging from 0.6 to 2.2 , occurred several hours before the mainshock. And Group B, integrating 35 earthquakes with the largest foreshock event $\left(\mathrm{M}_{\mathrm{L}}=4.0\right)$ (Table 1), started about 20 minutes before the mainshock. The focal mechanism of the largest foreshock was extremely similar to that of both the mainshock and the largest aftershock shown in Fig. 1.
Since these foreshocks were also recorded by seismic stations of CWBSN well positioned at distances of less than $10 \mathrm{~km}$, extremely small micro-earthquakes with magnitudes down to 0.4 could successfully be detected. A narrow seismic zone (about $5 \times 5 \mathrm{~km}^{2}$ ) was clearly delineated by two groups of foreshocks (Fig. 3), which had 64 events in total.
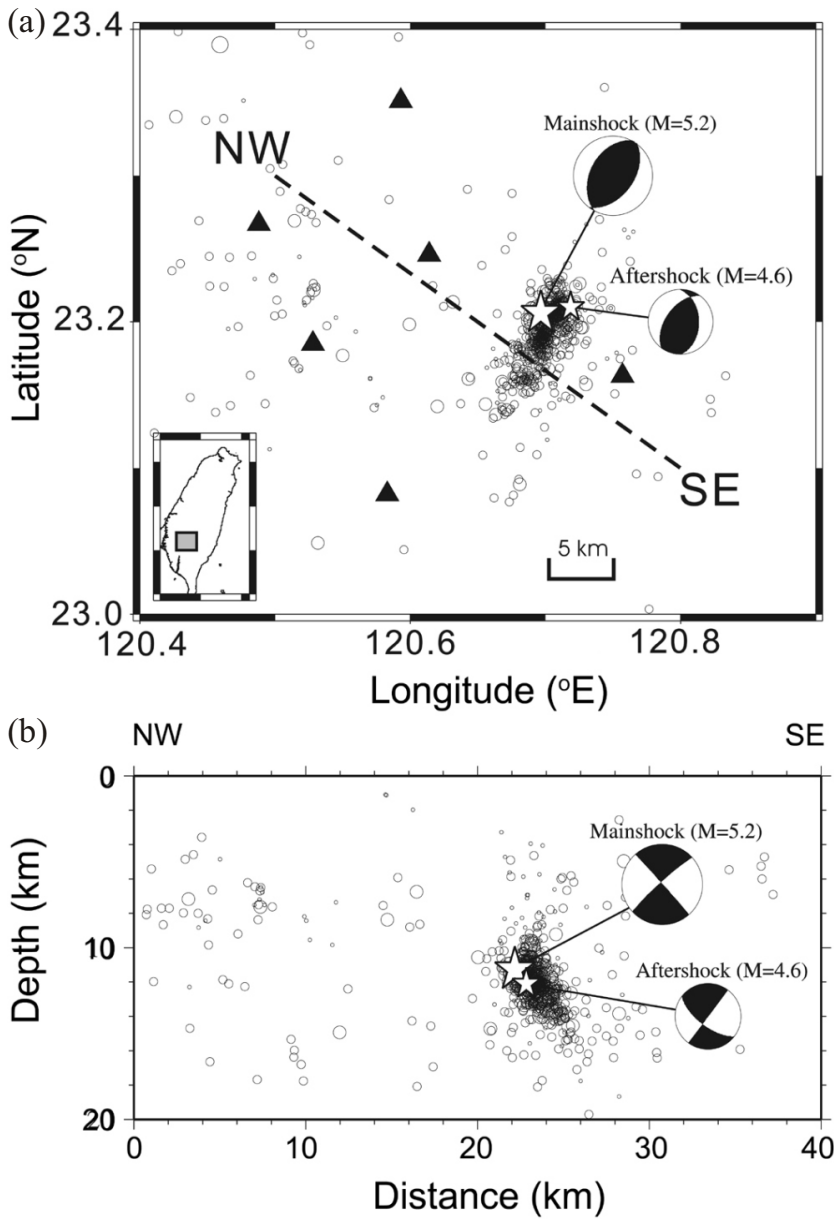

Fig. 1. Seismicity of the mainshock $\left(\mathrm{M}_{\mathrm{L}}=5.2\right)$ and its aftershocks of the Taoyuan earthquake sequence on 4 March 2008. (a) Locations of the mainshock (plus), aftershocks (circles, their sizes are dependent on earthquake magnitudes) and seismic stations (triangles). The focal mechanisms of the mainshock and one of the larger aftershocks are plotted in the low-hemisphere projection, and a box in the insert map shows the study area. (b) Depth projection of the earthquake sequence and focal mechanisms on the NW-SE profile.

Table 1. Locations and earthquake parameters of the mainshock and its large foreshock and aftershock.

\begin{tabular}{ccccccccc}
\hline $\begin{array}{c}\text { Time } \\
(\mathbf{d y} / \mathbf{h r} / \mathbf{m n})\end{array}$ & $\begin{array}{c}\text { Long. } \\
\mathbf{( d e g})\end{array}$ & $\begin{array}{c}\text { Lat. } \\
\mathbf{( d e g})\end{array}$ & $\begin{array}{c}\text { Depth } \\
\mathbf{( K m )}\end{array}$ & $\begin{array}{c}\text { Mag. } \\
\left.\mathbf{( M}_{\mathbf{L}}\right)\end{array}$ & $\begin{array}{c}\text { Strike } \\
(\mathbf{d e g})\end{array}$ & $\begin{array}{c}\text { Dip } \\
(\mathbf{d e g})\end{array}$ & $\begin{array}{c}\text { Rake } \\
(\mathbf{d e g})\end{array}$ & Remark \\
\hline $04 / 17 / 13$ & 120.6978 & 23.2083 & 11.58 & 4.0 & 29 & 46 & 90 & Foreshock \\
$04 / 17 / 31$ & 120.6957 & 23.2067 & 11.32 & 5.2 & 37 & 48 & 96 & Mainshock \\
$04 / 22 / 42$ & 120.7070 & 23.2125 & 11.95 & 4.6 & 216 & 53 & 114 & Aftershock \\
\hline
\end{tabular}




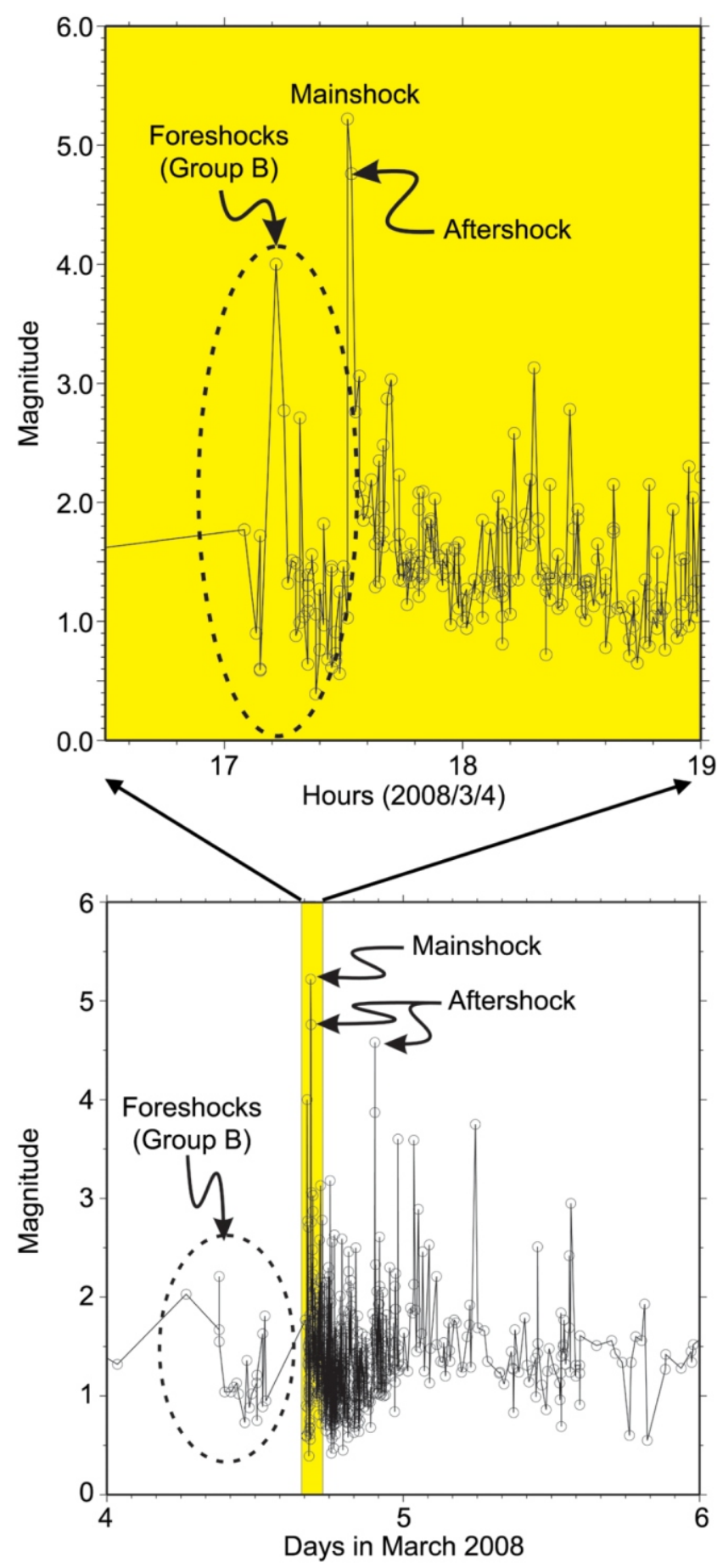

Fig. 2. Plots of earthquake magnitudes with time of the Taoyuan earthquake sequence on 4 March 2008.

Although the seismic zone of the foreshocks was smaller than the seismic zone $\left(10 \times 10 \mathrm{~km}^{2}\right)$ of the aftershocks, both seismic zones similarly overlaid the major fault plane.

\section{TEMPORAL $b$-VALUE VARIATIONS}

The series of fore- and aftershocks that occurred in the
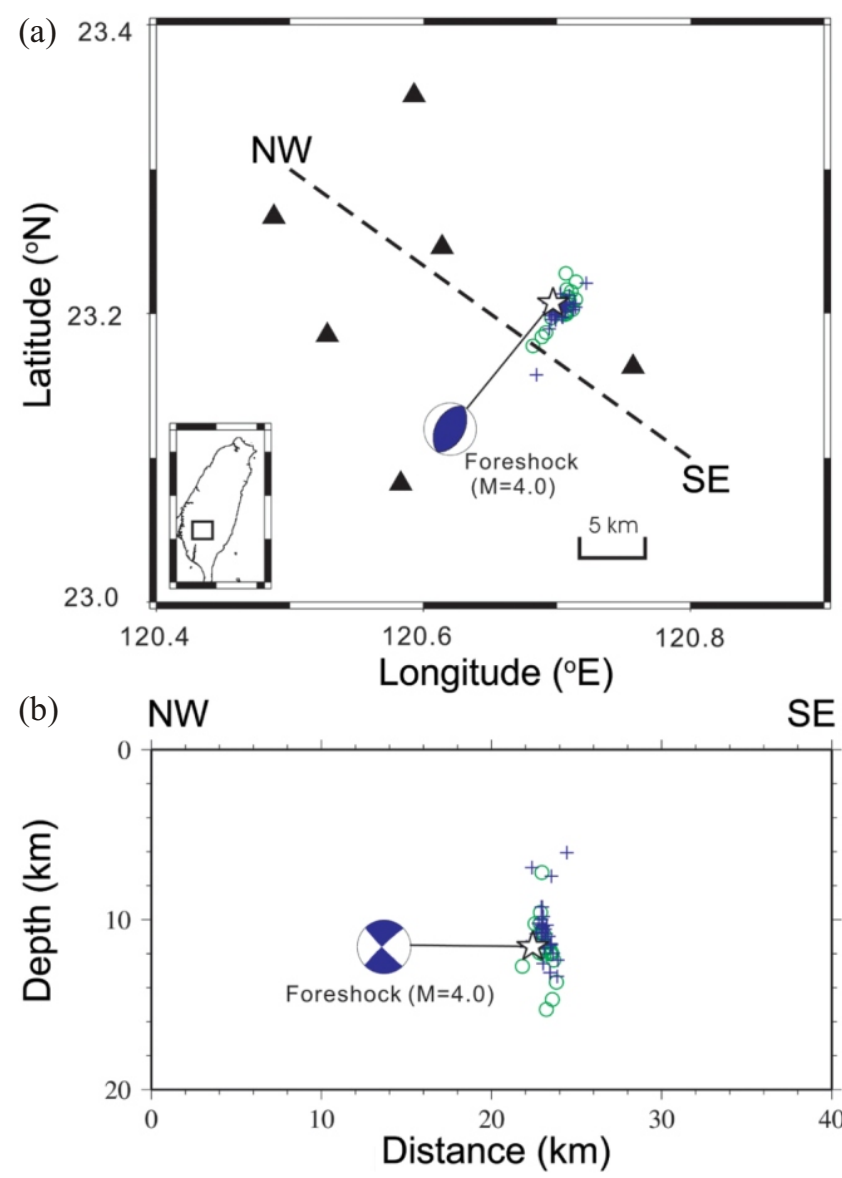

Fig. 3. (a) Foreshock locations of Groups A (circles) and B (pluses). A focal mechanism of the largest foreshock (star) is projected on the low-hemisphere. (b) Depth projection of the foreshocks and focal mechanism along the NW-SE profile.

Taoyuan earthquake sequence have provided an opportunity to examine temporal variations of $b$-values throughout the seismic cycle (Fig. 4). The $b$-values can be empirically estimated from the earthquake frequency-magnitude relationship (Ishimoto and Iida 1939; Gutenberg and Richter 1942), $\log \mathrm{N}=a-b \mathrm{M}$, where $\mathrm{N}$ is the number of earthquakes larger than magnitude $\mathrm{M}$, and $a$ and $b$ both are positive, real constants. First of all, a regression line with a $b$-value of $\sim 0.80$ is obtained from the several hundred aftershocks (Fig. 4a). Such a regression result is reliable because relativity $\left(\mathrm{R}^{2}\right)$ calculated by Microsoft Excel is greater than 0.99 . The $b$-value of $\sim 0.80$ is almost identical to the $b$-value of $\sim 0.81$ estimated from background seismicity during the past 17 years in the vicinity of this earthquake sequence area $\left(23.0-23.4^{\circ} \mathrm{N} ; 120.4-120.9^{\circ} \mathrm{E}\right)$. Second, a larger $b$-value of 1.25 with $\mathrm{R}^{2}>0.99$ is estimated from each of the 64 foreshocks of the two groups (A and B) that occurred along the major fault plane several hours and tens of minutes before the mainshock. So it is worth saying that the $b$-value of the foreshocks is significantly higher than the $b$-values of the aftershocks and background seismicity. 
(a)

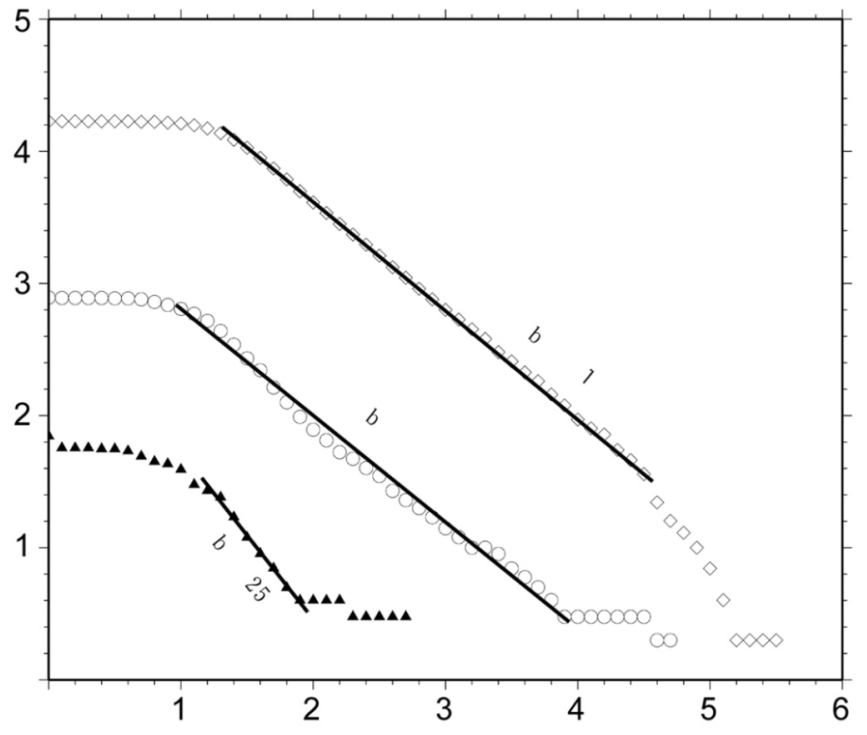

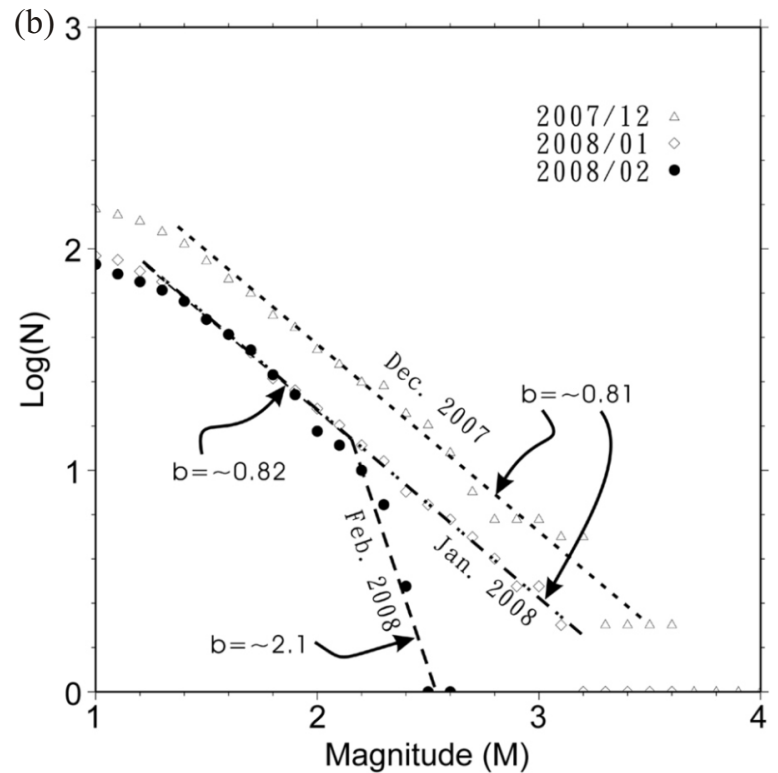

Fig. 4. Earthquake magnitude-frequency plots for determining $b$-values. (a) The $b$-values of background seismicity (1990 - 2006), aftershocks and foreshocks of the Taoyuan earthquake sequence. (b) The $b$-values of micro-earthquakes from one to three months before the Taoyuan earthquake.

In addition, the $b$-values of pre-shocks that occurred three months before the mainshock (Molchan et al. 1999) in the vicinity of the Taoyuan earthquake sequence are calculated (Fig. 4b). Similar to background seismicity, a $b$-value of $\sim 0.81$ was obtained from pre-shocks for the same area $\left(23.0-23.4^{\circ} \mathrm{N} ; 120.4-120.9^{\circ} \mathrm{E}\right)$ in December 2007 and January 2008 , respectively - three and two months before the Taoyuan earthquake sequence. However, there were some significant changes in the $b$-values for the same area in February 2008 (Fig. 4b), one-month prior to the earthquake sequence in Taoyuan. The regression line of the earthquake frequency-magnitude relationship can be separated into two segments. For the smaller earthquakes with local magnitudes $\left(\mathrm{M}_{\mathrm{L}}\right)$ between 1.4 and 2.0 , the $b$-value is around 0.82 with a regression relativity $\left(\mathrm{R}^{2}\right)$ of 0.97 . However, the $b$-value increases significantly (up to $\sim 2.1$ ) with a regression relativity $\left(\mathrm{R}^{2}\right)$ of 0.92 when a limit of micro-earthquakes of local magnitudes greater than 2.0 are taken into account. The increase in $b$-value results from the decrease of larger micro-earthquakes $\left(\mathrm{M}_{\mathrm{L}}>2.0\right)$ that took place just one month before the Taoyuan earthquake sequence.

\section{DISCUSSIONS}

The Taoyuan earthquake sequence gives an excellent case for efficiently representing seismic characteristics of fault growth in the crust. Foreshocks might well be considered as the crustal fractures during fault growth within the fault zone according to the following evidence. Firstly, seismicity of the foreshock zone similarly overlays that of the aftershock zone, showing that the foreshocks had taken place in the same major fault zone exactly as that of the mainshock and aftershocks. Secondly, the foreshocks occurred within a short time (from several hours to tens of minutes) before the mainshock, providing an unambiguous indication that they were immediate crustal fractures during fault growth within the major fault zone. Finally, the extreme closeness of focal mechanisms between the mainshock and the largest foreshock further confirms that they were under the same tectonic stress and then slipped along the same fault plane.

In fact, the faulting process of the Taoyuan earthquake $\left(\mathrm{M}_{\mathrm{L}}=5.2\right)$ sequence is extremely similar to the typical failure process observed in a brittle granite sample under controlled axial stress in laboratory testing. Based on a detailed study (Lockner et al. 1991), fracture nucleation and growth in brittle rocks can clearly be separated into three stages. At first, prior to fault nucleation, cracks are evenly distributed throughout the sample with the largest $b$-value. Secondly, fault nucleation starts with intense cracks, clustering in a narrow zone, and demonstrating an extremely low $b$-value. Finally, the fault grows with more cracks, developing along the nascent fault plane and the $b$-value recovers to about a half of that prior to nucleation. A similar rock failure process seems to have been observed in the Taoyuan earthquake sequence. The highest $b$-value $(\sim 2.1)$ for pre-shocks, i.e., the micro-earthquakes $\left(\mathrm{M}_{\mathrm{L}}>2.0\right)$ occurred one-month before the Taoyuan earthquake, perhaps reflecting distributed cracks at the pre-nucleation stage. It is significantly larger than the $b$-value of $\sim 0.81$ representing the background seismicity. Furthermore, the $b$-value of 1.25 estimated from two groups of foreshocks might largely represent fault growth 
before the mainshock. Unfortunately, the $b$-value of the fault nucleation phase could not be observed for the Taoyuan earthquake sequence as the nucleation process was most likely too short to produce enough earthquakes for determining any $b$-value.

In addition to fault growth, the Taoyuan earthquake sequence provides temporal $b$-value variations of postfaulting status and background seismicity for the understanding of a complete cycle of the faulting process in the crust (Fig. 5). Nearly similar $b$-values $(\sim 0.81$ and $\sim 0.80)$ estimated respectively from the aftershocks of the Taoyuan earthquake and long-term background seismicity might well be considered as a stable reference for showing increased $b$-values as the pre-nucleation and fault growth processes. Such a standard reference has not been achieved from rock failure processes under laboratory conditions (Lockner et al. 1991). Therefore, the $b=0.81$ obtained from background seismicity indicates general rock behavior under regional stress. A significant increase in the $b$-value to $\sim 2.1$, estimated from pre-shocks, occurred one month before the Taoyuan earthquake showing pre-nucleation characteristics in the vicinity of the nascent fault zone. The drop in the $b$-value to $\sim 1.25$, estimated from foreshock occurrences, represents fault growth. Unfortunately, no $b$-value is available for showing fault nucleation characteristics due to insufficient earthquakes within the short period of time that it took for nucleation to occur. Finally, the $b$-value returns to $\sim 0.80$ during the aftershock sequences.

Although the temporal $b$-value variations of the Taoyuan earthquake sequence are similar to those obtained from for the rock sample under laboratory conditions (Lockner et al. 1991), the high $b$-values obtained from the foreshocks of the Taoyuan sequence are different from many previous studies that show low $b$-values before the mainshock. The difference is most likely attributable to variations in foreshock selection. In the previous studies, most of the $b$-values were estimated by using earthquake data in the vicinity of the mainshock area. In this study, however, only foreshock events in the narrow fault zone have been considered. In fact, a high $b$-value in the fault zone might well be more appropriate in representing the faulting process and could thereby successfully provide a potential precursor for large earthquakes. However, some reservations and concerns do exist with this result. Although the observational data is well described, the total number of foreshocks (64) might not be high enough to obtain the high $b$-value actually obtained. Thus, the possibility of high $b$-values in the fault zone has to be confirmed through further observation.

\section{CONCLUSIONS}

This study gives complete temporal $b$-value variations for the entire faulting process of the Taoyuan earthquake $\left(\mathrm{M}_{\mathrm{L}}=5.2\right)$ sequence including pre-shocks, foreshocks, after-

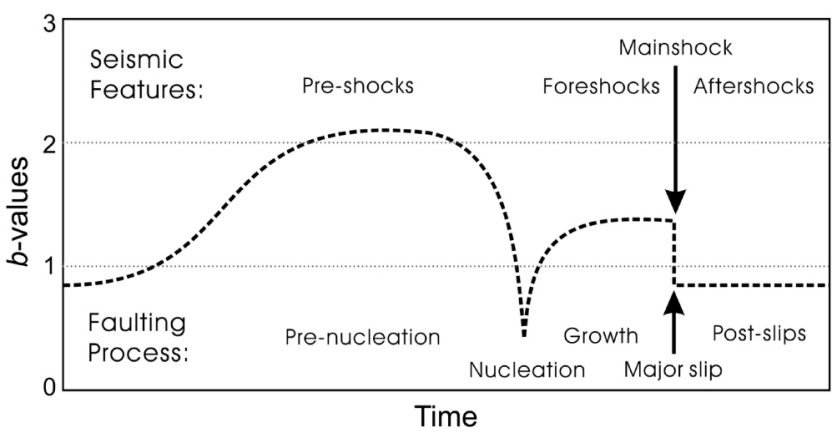

Fig. 5. Schematic plot of temporal $b$-value variations throughout a complete earthquake faulting process. The $b$-value increases at the pre-nucleation stage, decreases to a minimum at the time of fault nucleation and then recovers during the fault growth.

shocks and background seismicity. A high $b$-value of $\sim 2.1$ obtained from pre-shocks in the month prior to the mainshock is consistent with rock failure studies of the prenucleation stage under laboratory conditions. Foreshocks clustered along the nascent fault plane show a general feature of fault growth. The $b$-value of 1.25 from the foreshocks is also significantly higher than the $b$-values of 0.80 and 0.81 obtained from aftershocks and background seismicity. These seismic characteristics are generally consistent with observations of rock failure under controlled stress in laboratory experiments, which show that $b$-value decreases to a minimum at the time of fault nucleation and then recovers to over $50 \%$ of its initial value during the fault growth. Thus, high $b$-values of both the pre-shocks and foreshocks might be considered as a potential precursor for large earthquakes if other influential seismic characteristics are confirmed by further observation.

Acknowledgements The author would like to thank the Central Weather Bureau, Taipei, Taiwan for providing the earthquake data. Discussions with M. Ando were very helpful. The valuable comments of C. Y. Wang and two anonymous reviewers are appreciated. This research work was partially supported by the National Science Council and Central Weather Bureau, Taipei, Taiwan.

\section{REFERENCES}

Amitrano, D., 2003: Brittle-ductile transition and associated seismicity: Experimental and numerical studies and relationship with the $b$ value. J. Geophys. Res., 108, 2044, doi: 10.1029/2001JB000680. [Link]

Comninakis, P., J. Drakopoulos, G. Moumoulidis, and B. Papazachos, 1968: Foreshock and aftershock sequences of the Cremasta earthquake and their relation to the waterloading of the Cremasta artificial lake. Annali di Geofisica, 21, 39-71.

Enescu, B. and K. Ito, 2001: Some premonitory phenomena of the 1995 Hyogo-ken Nanbu earthquake: Seismicity, $b$-value 
and fractal dimension. Tectonophysics, 338, 297-314, doi: 10.1016/S0040-1951(01)00085-3. [Link]

Gupta, H. K., B. K. Rastogi, and H. Narain, 1972: Common features of the reservoir associated seismic activities. Bull. Seismol. Soc. Am., 62, 481-492.

Gutenberg, B. and C. R. Richter, 1942: Earthquake magnitude, intensity, energy and acceleration. Bull. Seismol. Soc. Am., 32, 163-191.

Ishimoto, M. and K. Iida, 1939: Observations sur les séismes enregistrés par le microsismographe construit dernièrement. Bull. Earthq. Res. Inst. Univ. Tokyo, 17, 443-478. (in Japanese)

Lee, Q., J. Chen, L. Yu, and B. Hao, 1978: Time and space scanning of the $b$-value: A method for monitoring the development of catastrophic earthquakes. Ti Chiu Wu Li Hsueh Pao, 21, 101-125. (in Chinese)

Lin, C. H., 2002: Active continental subduction and exhumation: the Taiwan orogeny. Terr. Nova, 14, 281-287, doi: 10.1046/j.1365-3121.2002.00421.x. [Link]

Lockner, D. A., J. D. Byerlee, V. Kuksenko, A. Ponomarey, and A. Sidorin, 1991: Quasi-static fault growth and shear fracture energy in granite. Nature, 350, 39-42, doi: 10.1038/ 350039a0. [Link]

Main, I. G., P. G. Meredith, and P. R. Sammonds, 1992: Temporal variations in seismic event rate and $b$-values from stress corrosion constitutive laws. Tectonophysics, 211, 233-245, doi: 10.1016/0040-1951(92)90061-A. [Link]

Molchan, G. M., T. L. Kronrod, and A. K. Nekrasova, 1999: Immediate foreshocks: Time variation of the $b$-value.
Phys. Earth Planet. Inter., 111, 229-240, doi: 10.1016/ S0031-9201(98)00163-0. [Link]

Parsons, T., 2007: Forecast experiment: Do temporal and spatial $b$ value variations along the Calaveras fault portend $M \geq 4.0$ earthquake? J. Geophys. Res., 112, B03308, doi: 10.0129/2006JB004632. [Link]

Scholz, C. H., 1968: The frequency-magnitude relation of microfractureing in rock and its relation to earthquakes. Bull. Seismol. Soc. Am., 58, 399-415.

Schorlemmer, D., S. Weiner, and M. Wyss, 2005: Variations in earthquake-size distribution across different stress regimes. Nature, 437, 539-542, doi: 1-.1038/nature04094. [Link]

Shin, T. C., K. W. Kou, W. H. K. Lee, T. L. Teng, and Y. B. Tsai, 2000: A preliminary report on the 1999 Chi-Chi (Taiwan) earthquake. Seismol. Res. Lett., 71, 23-29.

von Seggern, D., 1980: A random stress model for seismicity statistics and earthquake prediction. Geophys. Res. Lett., 7, 637-640, doi: 10.1029/GL007i009p00637. [Link]

Wu, K., S. Lu, K. Tian, W. Huang, M. Yue, H. Wu, X. Cao, and H. Chen, 1976: Certain characteristics of Haicheng earthquake ( $\mathrm{M}=7.3)$ sequence. Ti Chiu Wu Li Hsueh Pao, 19, 95-109.

Wu, Y. M. and L. Y. Chiao, 2006: Seismic quiescence before the 1999 Chi-Chi, Taiwan, $M_{\mathrm{w}} 7.6$ earthquake. Bull. Seismol. Soc. Am., 96, 321-327, doi: 10.1785/0120050069. [Link]

Yeh, Y. H., E. Barrier, C. H. Lin, and J. Angiler, 1991: Stress tensor analysis in the Taiwan area from focal mechanism of earthquakes. Tectonophysics, 200, 267-280, doi: 10.1016/ 0040-1951(91)90019-O. [Link] 